\section{Frustration effects after varied numbers of partial and continuous reinforcements: Incentive differences as a function of reinforcement percentage*}

\author{
JAMES J. HUG \\ University of Toronto, Toronto, Canada
}

Magnitude of the frustration effect (FE) was assessed after 16, 40, and 64 acquisition trials under continuous (CRF) and partial (PRF) reinforcement conditions. The data indicated that FE magnitude increased with the number of training trials under both reinforcement schedules and that, although the effect was more pronounced under CRF conditions with relatively few reinforcements, there was no difference in the magnitude of the effect as a function of CRF vs PRF after additional reinforcements. Assuming that the strength of incentive or expectancy is a factor in the magnitude of the FE, these data can be taken as confirming Spence's (1960) speculation that PRF decelerates the conditioning of incentive but does not affect its asymptotic strength.

In what has come to be referred to as the Amsel (1958)-Spence (1960) theory of instrumental reward learning, the strength of primary frustration $\left(R_{F}\right)$ has been assumed to vary as a positive function of the strength of anticipation of reinforcement $\left(r_{R}-s_{R}\right)$. Since it has also been assumed that the strength of $r_{R}-s_{R}$ is partially determined by the number of reinforcements, the magnitude of primary frustration should vary directly with the number of prior reinforcements. The recent data of Patten \& Myers (1970), Stimmel \& Adams (1969), and of Yelen (1969) tend to support this proposition.

Spence has further addressed himself to the strength of $\mathrm{r}_{\mathrm{R}}-\mathrm{s}_{\mathrm{R}}$ under continuous (CRF) vs partial (PRF) reinforcement conditions. He tentatively assumed (1960, Chap. 6) that early in training the strength of $r_{R}-S_{R}$ will be weaker in the PRF condition, which typically involves only half as many rewards as compared to CRF at any point in training, but that relatively later in acquisition, the difference in strength of $r_{R}-s_{R}$ will be markedly reduced, if not eliminated entirely. One way in which Spence's further hypothesis can be examined is in the double-runway situation in which the number of reinforcements can be varied, and hence the strength of $r_{R}-s_{R}$ manipulated, in the first runway and the magnitude of $R_{F}$ can be measured in the second. (Using this type

*Supported by Research Grants GB-3772 from the National Science Foundation and APA-72 from the National Research Council of Canada, both of which were awarded to Professor Abram Amsel. This experiment was conducted according to the APA statement of "Principles for the Care and Use of Animals," June 26, 1968. Reprint requests should be sent to Department of Correctional Services. Research Branch. Parliament Buildings, Toronto, Canada.

of procedure, differences in the strength of primary frustration are inferred from differences in the magnitude of the frustration effect (FE), which is the difference between second-runway performance following reward and nonreward in the first runway.) In the present experiment, number of reinforcements and CRF vs PRF were varied orthogonally.

If differences in FE magnitude as a function of CRF vs PRF were found after a small number of reinforcements (acquisition trials) but not after a larger number, these differences might be interpreted as supporting Spence's hypothesis. If, on the other hand, the CRF vs PRF difference in FE magnitude were Table

FE Magnitudes as Functions of Trials and Reinforcements

\begin{tabular}{|c|c|c|c|c|c|c|c|c|}
\hline \multirow{2}{*}{$\begin{array}{l}\text { Four- } \\
\text { Trial } \\
\text { Block }\end{array}$} & \multicolumn{2}{|c|}{ Group $0 \mathrm{C} / 80 \mathrm{P}$} & \multicolumn{2}{|c|}{ Group $16 \mathrm{C} / 64 \mathrm{P}$} & \multicolumn{2}{|c|}{ Group $40 \mathrm{C} / 40 \mathrm{P}$} & \multicolumn{2}{|c|}{ Group $64 \mathrm{C} / 16 \mathrm{P}$} \\
\hline & $\begin{array}{c}\text { Reinforce- } \\
\text { ment }\end{array}$ & $\mathrm{FE}$ & $\begin{array}{c}\text { Reinforce- } \\
\text { ment }\end{array}$ & $\mathrm{FE}$ & $\begin{array}{c}\text { Reinforce- } \\
\text { ment }\end{array}$ & $\mathrm{FE}$ & $\begin{array}{c}\text { Reinforce- } \\
\text { ment }\end{array}$ & FE \\
\hline 1 & $1-2$ & -.02 & $1-4^{*}$ & .04 & $1-4^{*}$ & .02 & $1-4^{*}$ & .01 \\
\hline 2 & $3-4$ & .05 & $5-8 *$ & .00 & $5-8 *$ & .08 & $5-8^{*}$ & .04 \\
\hline 3 & $5-6$ & -.08 & $9-12^{*}$ & -.03 & $9-12^{*}$ & -.03 & $9-12 *$ & -.02 \\
\hline 4 & $7-8$ & .01 & $13-16^{*}$ & -.01 & $13-16^{*}$ & -.05 & $13-16^{*}$ & .03 \\
\hline 5 & $9-10$ & -.06 & $17-18$ & .19 & $17-20^{*}$ & -.01 & $17-20^{*}$ & .07 \\
\hline 6 & $11-12$ & .03 & $19-20$ & .23 & $21-24^{*}$ & .03 & $21-24^{*}$ & -.06 \\
\hline 7 & $13-14$ & .13 & $21-22$ & .30 & $25-28$ * & .01 & $25-28^{*}$ & .03 \\
\hline 8 & $15-16$ & .09 & $23-24$ & .28 & $29-32 *$ & .04 & $29-32 *$ & .05 \\
\hline 9 & $17-18$ & .15 & $25-26$ & .31 & $33-36 *$ & .06 & $33-36 *$ & .02 \\
\hline 10 & $19-20$ & .27 & $27-28$ & .18 & $37-40^{*}$ & .02 & $37-40^{*}$ & .01 \\
\hline 11 & $21-22$ & .22 & $29-30$ & .29 & $41-42$ & .48 & $41-44^{*}$ & .05 \\
\hline 12 & $23-24$ & .31 & $31-32$ & .37 & $43-44$ & .53 & $45-48 *$ & .03 \\
\hline 13 & $25-26$ & .39 & $33-34$ & .40 & $45-46$ & .45 & $49-52^{*}$ & -.01 \\
\hline 14 & $27-28$ & .46 & $35 \cdot 36$ & .35 & 47.48 & .49 & $53-56^{*}$ & .02 \\
\hline 15 & $29-30$ & .40 & $37-38$ & .43 & 49.50 & .52 & $57-60^{*}$ & .01 \\
\hline 16 & $31-32$ & .45 & $39-40$ & .49 & 51.52 & .57 & $61-64 *$ & .03 \\
\hline 17 & $33-34$ & .49 & 41.42 & .52 & $53-54$ & .53 & $65-66$ & .55 \\
\hline 18 & $35-36$ & .56 & 43.44 & .50 & $55-56$ & .58 & $67-68$ & .62 \\
\hline 19 & $37-38$ & .50 & $45-46$ & .54 & $57-58$ & .54 & $69-70$ & .59 \\
\hline 20 & 39.40 & .53 & $47-48$ & .59 & 59.60 & .61 & $71-72$ & .66 \\
\hline
\end{tabular}

Note-FE magnitudes are the differcnces between Alley 2 speeds (feet per second) after nonreward and reward in Alley 1. calculated in blocks of four trials. * represents CRF trials.

found to be independent of the relative amount of training, then one might conclude that percentage of reinforcement has an effect on the asymptotic strength of $\mathrm{T}_{\mathrm{R}}-\mathrm{S}_{\mathrm{R}}$.

Forty male albino rats of the Wistar strain, approximately 50-60 days old, were obtained from Woodlyn Farms, Guelph, Ontario. For 8 days they were housed two per cage and were given ad lib food with tetracycline added to the drinking water. After 12 days on a $12-\mathrm{g} / 23-\mathrm{h}$ food-deprivation schedule (which was continued throughout the experiment) with ad lib tap water and living in individual cages, 3 days of runway exploration began. The Ss were $73-83$ days old on the first day of acquisition.

An L-shaped double-alley runway was used. Alley 1 was painted flat black, covered with clear Plexiglas, and contained in series: an 11-in. entrybox, 11-in. startbox, and 47-in. alley. Guillotine doors separated the start and entry chambers and formed a 21-in. goalbox (GB). The food pellet was concealed in a small black metal cup placed approximately $2 \frac{1 / 2}{2}$ in. above the runway floor on the side of the end wall opposite to the door leading to Alley 2. Alley 2 was placed perpendicular to Alley 1, was 45 in. long, unpainted pine, and had a hardware cloth floor with a 14-in. GB. It was also covered with clear Plexiglas. Guillotine doors controlled access to Alley 2 and formed the GB. In the second alley the food pellet was concealed in a gray metal trough, extending the length of the end wall at a 1 
height of $2 \frac{1}{2}$ in. above the floor. Both runways were $2 \cdot 7 / 8 \mathrm{in}$. wide $x 3.7 / 8 \mathrm{in}$. high. Microswitches on the start doors, silent photoelectric circuitry, and .01-sec clocks were used to obtain 1-ft measures of response time. In Alley 1 these measures were obtained over the first 36 in. of the runway; in Alley 2 measures were obtained over the first 24 in.

All Ss received 80 acquisition trials with a 300-mg food pellet in each GB. The two daily trials were separated by an ITI of approximately $30 \mathrm{~min}$. The $\mathrm{Ss}$ were randomly assigned to four groups on arrival. Group $0 \mathrm{C} / 80 \mathrm{P}$ received $50 \%$ reinforcement in $\mathrm{GB} 1$ on all 80 trials. Groups $16 \mathrm{C} / 64 \mathrm{P}, 40 \mathrm{C} / 40 \mathrm{P}$, and $64 \mathrm{C} / 16 \mathrm{P}$ were switched from CRF to $50 \%$ after 16 , 40 , and 64 trials, respectively. All groups received CRF in GB2 throughout. The Ss were run as two squads, with an equal number of Ss from each group per squad. Running order varied randomly across days; the same running order was followed for the two squads on both trials of any experimental day. The Ss were not run on weekends. The $50 \%$ reinforcement schedule consisted of the recursive sequence, RRNNRNNRNRRNNNRR, having all four first-order transitional probabilities equal to .50 ; Ss began this sequence at the $1 \mathrm{st}, 5 \mathrm{th}, 9 \mathrm{th}$, and 13th elements so that any given experimental trial consisted of both $\mathrm{R}$ and $\mathrm{N}$ goal events.

The Ss were hand carried from the colony to the experimental room. After orienting to the Alley 1 start door, they were released into the first runway. On rewarded GB1 trials they were released into the second runway 5 sec after completion of eating; approximately $15 \mathrm{sec}$ were required to consume the $300-\mathrm{mg}$ pellet. On nonrewarded GB1 trials they were released into Alley 2 after a 20-sec confinement to GB1. Removal from GB2 occurred upon completion of eating.

\section{RESULTS}

The five latency measures were converted to speed scores by reciprocal transformation. Alley 1 data are irrelevant here and are not presented.

Alley 2 data were analyzed as a Groups (4) by Goal Event (2) by Blocks (20) design. The triple interaction among these variables was significant in both the start, $\mathrm{F}(57,684)=9.56$, and $\mathrm{run}$, $F(57,684)=3.56$, measures, both $p<.01$. Separate analyses of variance were computed on the trials following reward in GB1 (TFR). As there were no groups or Groups by Goal Event effects $(p>.10)$ in either measure, it would appear that the differences in FE magnitude reflect differences in performance on trials following GB1 nonreward (TFN) but not TFR differences. The further analyses necessitated by the significant triple interaction were based on blocks of trials as well as on blocks of reinforcements.

Table 1 contains FE-magnitude data for the four groups on the start measure, along with the number of reinforcements that had been received prior to and during a particular block of trials. Detailed data for the run measure are virtually identical and are not included in Table 1 . The Groups by Goal Event interaction, indicative of group differences in FE magnitude, was significant $(p<.05)$ on all blocks of trials except for Blocks 1-4 (start and run measures), 5 (run), 7 (run), and 17 (start and run). Subsequent Tukey-A contrasts for those blocks having a significant Groups by Goal Event interaction served to further isolate group differences in $\mathrm{FE}$ magnitude. During Blocks 5-10 (Trials 17.40), Groups $0 \mathrm{C} / 80 \mathrm{P}$ and $16 \mathrm{C} / 64 \mathrm{P}$ were receiving partial reinforcement necessary to measure the FE. For the 10 sets of contrasts in both start and run measures, Group 16C/64P showed an $\mathrm{FE}$ on eight occasions, as inferred by $\mathrm{FE}$ magnitudes significantly greater than for both Groups $40 \mathrm{C} / 40 \mathrm{P}$ and $64 \mathrm{C} / 16 \mathrm{P}$, which were then receiving only $\mathrm{R}$ trials in GB1. In contrast, Group $0 \mathrm{C} / 80 \mathrm{P}$, which received PRF throughout and hence fewer reinforcements, showed only one FE. Furthermore, the FE magnitude in Group $16 \mathrm{C} / 64 \mathrm{P}$ was greater than in Group $0 \mathrm{C} / 80 \mathrm{P}$ on 8 of these 10 occasions.

The next group of contrasts encompassed Blocks 11-16 (Trials 41-64). Over these blocks all groups except $64 \mathrm{C} / 16 \mathrm{P}$ were on partial reward in the first alley and, in principle, could show the FE. Groups $40 \mathrm{C} / 40 \mathrm{P}$ and $16 \mathrm{C} / 64 \mathrm{P}$, which had received, respectively, 40 and 28 reinforcements prior to Trial 41 , gave FEs on all 12 occasions, as inferred by $\mathrm{FE}$ magnitudes greater than those for Group 64C/16P, which was still a control, i.e., $\mathrm{CRF}$, condition. By the same criterion, Group $0 \mathrm{C} / 80 \mathrm{P}$, having received 20 prior reinforcements, gave 10 FEs. Comparisons among the three then-partial groups indicated that on seven occasions FE magnitude was larger in Group $40 \mathrm{C} / 40 \mathrm{P}$ than in Group $0 \mathrm{C} / 80 \mathrm{P}$. On two occasions Group $40 \mathrm{C} / 40 \mathrm{P}$ gave a larger $\mathrm{FE}$ than did Group 16C/64P. However, the difference in $\mathrm{FE}$ magnitudes between this latter group and Group $0 \mathrm{C} / 80 \mathrm{P}$ was reliable on only 1 of the 12 occasions.

The final group of contrasts involved Blocks 17-20 (Trials 65-80). Up to this point, the respective groups had received $32,40,52$, and 64 reinforcements. In the six sets of contrasts, no significant differences were obtained. Examination of Table 1 and consideration of the statistical summary apparently warrants the following conclusions. Regardless of the number of prior CRF trials, all groups gave reliable FEs. For groups having relatively few CRF trials prior to partial reinforcement. i.c. Groups $0 \mathrm{C} / 80 \mathrm{P}$ and $16 \mathrm{C} / 64 \mathrm{P}$. FE magnitude increased from cero to a rather substantial level. Alternatively, for groups having more prior CRF trials, i.e., Groups $40 \mathrm{C} / 40 \mathrm{P}$ and $64 \mathrm{C} / 16 \mathrm{P}$. FE magnitude was large and relatively constant over the series of partial reinforcement trials. Comparing FE magnitudes after 16 CRF (16 reinforcements) or 16 PRF (8 reinforcements) trials, there was apparently a difference that was maintained until the groups had received, respectively, 28 and 20 reinforcements. Comparing after 40 CRF (40 reinfurcements) and 40 PRF (20 reinforcements) trials, the difference in $\mathrm{FE}$ magnitudes again appeared to be substantial and was maintained until Trial 64, at which point 52, as opposed to 32 , reinforcements had been received. And finally, there appeared to be no difference in FE magnitudes after $64 \mathrm{CRF}$ vs PRF trials, as Groups $O C / 80 \mathrm{P}$ and $64 \mathrm{C} / 16 \mathrm{P}$ did not differ reliably during Trials 65-80. Looking next at FE magnitude after 0,16 , 40, and 64 CRF trials, a negatively accelerated increasing function results. Thus Group $0 \mathrm{C} / 80 \mathrm{P}$ showęd no immediate FE, Group 16C/64P had an initial FE of approximately .20 (TFN-TFR speeds in feet per second), Group 40C/40P had one of approximately .50, and Group 64C/16P had one of approximately .55 .

A second set of analyses was based on data points for which the number of prior reinforcements was constant but the number of prior trials varied as the between-group parameter. The FE can be measured in both Groups $0 \mathrm{C} / 80 \mathrm{P}$ and $16 \mathrm{C} / 64 \mathrm{P}$ as these $\mathrm{Ss}$ obtained reinforcements $17-40$. The former group had had 32 prior trials on a partial schedule, and the latter 16 on CRF. The Groups by Goal Event interaction was significant, when blocks was used as a repeated measure, but in the start measure only, $F(1,684)=16.33, \quad p<.01$. This interaction resulted from the larger $\mathrm{FE}$ displayed by Group 16C/64P. The FE can also be measured in Groups 16C/64P and $40 \mathrm{C} / 40 \mathrm{P}$ as these $\mathrm{Ss}$ obtained their 41 st 48 th reinforcements. The former group had, at that point, received 16 reinforcements on a partial schedule and 24 on CRF, while the latter had received all 40 prior rewards on CRF. In this case, the Groups by Goal Event by Blocks analysis of variance revealed no significant Grouns by Goal Event or triple interaction in elther start or run measures. Looking at percentage reward effects when number of prior reinforcements had been equated, 
there is a weak indication that schedule cffects are of consequence with relatively fow rewards, but apparently no evidence for differential $F E$ magnitude resulting from different percentages of reinforcement after additional training trials had been given.

\section{DISCUSSION}

Assuming that the magnitude of primary frustration $\left(R_{\mathrm{I}}\right)$, which is indexed by the $\mathrm{FE}$, is influenced by the strength of anticipation of reward $\left(r_{R}-s_{R}\right)$ or, in Spence's (1960) terms, incentive motivation $(\mathrm{K})$, the present results might be interpreted as suggesting that $r_{R}-s_{R}$ reaches the same asymptotic strength under partial as under continuous reinforcement conditions. After a relatively small number of acquisition trials, the FE was larger after prior CRF than after prior PRF training. However, this difference was not obtained after a larger number of acquisition trials.

Logically, if it is assumed that $r_{R} \cdot s_{R}$ reaches the same asymptotic value under the two different percentages, it follows that the strength of $r_{R}-s_{R}$ is not reduced on $\mathrm{N}$ trials of the partial-reward schedule. This implication is apparently in agreement with the present data, especially after a relatively large number of reinforcements. Thus, in the analyses reported here, there was minimal evidence for differences in FE magnitude as a function of percentage of reward, when the number of prior rewards had been equated.

Although the interpretation of these data is somewhat speculative, the data themselves are in agreement with previous studies of this kind. Examining FE magnitude as a function of number of prior CRF rewards, Stimmel \& Adams (1969) found a positive relationship using 35 vs 75 trials (270-mg food reward), as did Yelen (1969), who compared 12,36, and 60 CRF trials (97-mg food reward). In a slightly different paradigm, Patten \& Myers (1970) found a larger FE after 72 than after 12 CRF trials, when the effect was obtained by reducing GBl reward from $360 \mathrm{mg}$ to 45 mg. Furthermore, Amsel \& Ward (1965, Experiment 2) noted a larger FE after 48 , when compared to 12 , reinforcements prior to a test phase involving discrimination learning in the first alley and the measurement of the $\mathrm{FE}$ in the second. Finally, Wagner (1959) found no evidence for differential $\mathrm{FE}$ magnitude when conditions involving 80 prior CRF vs PRF trials (100-mg food reward) were contrasted.

\section{REFERENCES}

AMSEL, A. The role of frustrative nonreward in noncontinuous reward situations. Psychological Bulletin, 1958, 55, 102-119.

AMSEL, A., \& WARD, J. S. Frustration and persistence: Resistance to discrimination following prior experience with the discriminanda. Psychological Monographs, 1965, 79(4, Whole No. 597).

PATTEN, R. L., \& MYERS, D. B. Number of training trials and frustration effects of nonzero reward reduction in the double alley. Psychonomic Science, 1970, 18, 291-292.

SPENCE, K. W. Behavior theory and learning. Englewood Cliffs, N.J: Prentice-Hall, 1960.

STIMMEL, D. T., \& ADAMS, P. C. The magnitude of the frustration effect as a function of the number of previously reinforced trials. Psychonomic Science, 1969 , $16,31-32$

WAGNER, A. R. The role of reinforcement and nonreinforcement in an "apparent frustration effect." Journal of Experimental Psychology, $1959,57,130-136$

YELEN, D. Magnitude of the frustration effect and number of training trials. Psychonomic Science, 1969, 15, 137-138.

\title{
Number of food pellets and the development of the frustration effect*
}

\author{
JAMES J. HUG \\ University of Toronto, Toronto, Canada
}

Following few-trials partial-reinforcement studies, the effect of number of food pellets (total magnitude of reward equated) on the development of the frustration effect (FE) was investigated. Multiple pellets in the first goalbox resulted in more rapid development of the FE but did not affect its terminal magnitude. In contrast. the number of pellets in the second goalbox had no effect on either the rate of development of the terminal strength of the FE. The results were seen as supporting the frustration-theory account of few-trials experiments.

A rather sizable body of experimental data suggests that the presence or absence of the partial-reinforcement effect (PRE) after very limited acquisition, i.e., two to
Amsel et al assumed that multiple food pellets or wet mash rewards, as contrasted to one or two food pellets, serve two functions: (1) accelerate the conditioning of expectancy $\left(\mathrm{r}_{\mathrm{R}}-\mathrm{s}_{\mathrm{R}}\right)$ so that extinction is frustrating $\left(R_{F}\right)$ after multiple-pellet acquisition but not after single-pellet training, and (2) result in sufficient $r_{R}-s_{R}$ so that nonrewarded acquisition trials produce $R_{F}$ and thereby allow for the development of the persistence mechanism, i.e., the counterconditioning of the instrumental response to anticipatory frustration $\left(\mathrm{r}_{\mathrm{F}}-\mathrm{S}_{\mathrm{F}}\right)$. Although a subsequent study by these authors (Amsel, Surridge, \& Hug, 1969) cast some doubt on the validity of the second assumption, the first remains viable as an explanatory device.

One implication of the first assumption is that primary frustration $\left(R_{F}\right)$ will develop more rapidly, and possibly have a higher asymptotic value, when multiple pellets, as opposed to few, are used. This implication derives from Amsel's (1958) basic assumption that $R_{F}$ varies directly with the strength of $r_{R}-s_{R}$. Accordingly, the frustration effect $(\mathrm{FE})$, from which the strength of $R_{F}$ is inferred, was studied as a function of multiple- vs single-pellet reinforcements with the total magnitude of reinforcement equated.

\section{METHOD}

Forty male albino rats of the Wistar strain were obtained from Woodlyn Farms, Guelph, Ontario, and were approximately 80-90 days old on arrival. They were immediately placed on a $12-\mathrm{g} / 23-\mathrm{h}$ food-deprivation schedule, given $30 \mathrm{~min}$ after completion of the daily session, with ad lib drinking water. The Ss were handled for $1 \mathrm{~min}$ daily for the 16 days prior to pretraining.

An L-shaped double-alley runway was used. Alley 1 consisted of an 11-in. entrybox, an 11 -in. startbox, and a 47 -in. alley. It was painted flat black. Guillotine doors separated the start and entry chambers and formed a 21-in. goalbox (GB). The food pellet was concealed in a small black metal cup placed approximately $2 \frac{1}{2} \mathrm{in}$. above the runway floor on the side of the end wall opposite the door leading to Alley 2. Alley 2 was placed perpendicular to Alley 1, was 45 in.

\footnotetext{
*Supported by Research Grants GB-3772 from the National Science Foundation and APA-72 from the National Research Council of Canada, both of which were awarded to Professor Abram Amsel. This experiment was conducted according to the APA statement of "Principles for the Care and Use of Animals," June 26, 1968. Requests for reprints should be sent to Department of Correctional Services, Research Branch, Parliament Buildings, Toronto, Canada.
} 